\title{
Management of Narrow Edentulous Space of Two Missing Teeth in Maxillary Aesthetic Zone Using Implant as Abutment with a Cantilevered Tooth - a Case Report
}

\author{
Dinesh Ram Raja ${ }^{1, *}$, Thiyaneswaran Nesappan ${ }^{2}$ \\ ${ }^{1}$ Saveetha Dental College, Chennai, Tamilnadu \\ ${ }^{2}$ Department of Implantology, Saveetha Dental College, Chennai, Tamilnadu \\ *Corresponding author: avdineshramraja@gmail.com
}

Received June 07, 2014; Revised June 17, 2014; Accepted June 29, 2014

\begin{abstract}
The need for replacing missing teeth is obvious when comes to anterior segment of the mouth. The use of implants with single crowns may not be always successful in replacing two missing teeth in an insufficient edentulous span. Hence use of single implants with two splinted crowns with a cantilevered tooth is critical for the success of the treatment. This clinical report deals with the treatment using a single implant in management of replacing two missing teeth in a narrow edentulous space in a patient with generalized crowding.
\end{abstract}

Keywords: implant, cantilever, splinted crowns

Cite This Article: Dinesh Ram Raja, and Thiyaneswaran Nesappan, "Management of Narrow Edentulous Space of Two Missing Teeth in Maxillary Aesthetic Zone Using Implant as Abutment with a Cantilevered Tooth - a Case Report.” International Journal of Dental Sciences and Research, vol. 2, no. 4 (2014): 76-79. doi: 10.12691/ijdsr-2-4-2.

\section{Introduction}

The need for replacing missing teeth is obvious to the patient when the edentulous space is in the anterior segment of the mouth, but it is equally important in the posterior region [1]. Implant placement and restoration to replace missing teeth in the esthetic zone is an especially challenging area for the clinician, particularly in sites with deficiencies in soft tissue or bone. Preservation or creation of a soft tissue scaffold needed to create the illusion of a natural tooth is often challenging and difficult to achieve $[2,3]$. The purpose of this paper is to report a case where replacement of two missing teeth was done by using single implant with two splinted crowns with a cantilevered tooth.

\section{Case Report}

A 27 year old lady reported with a complaint of missing lateral and canine in the upper left anterior region of the jaw. On clinical examination she had class-I molar relation with crowding in anterior region. On radiological examination (CBCT Maxilla) we determined that the mesiodistal space is insufficient to place two implants. Sufficient bone width and height were present in between missing 22 and 23 with a bone defect in mid labial cortical plate [Figure 1]. A diagnostic wax up was made to evaluate the final outcome [Figure 2 a \& Figure 2 b]. Finally we decided to perform placement of a single implant in between 22 and 23 with the correction of bone defect using bone graft and in rehabilitation, a bridge of 2 units with a cantilevered tooth.

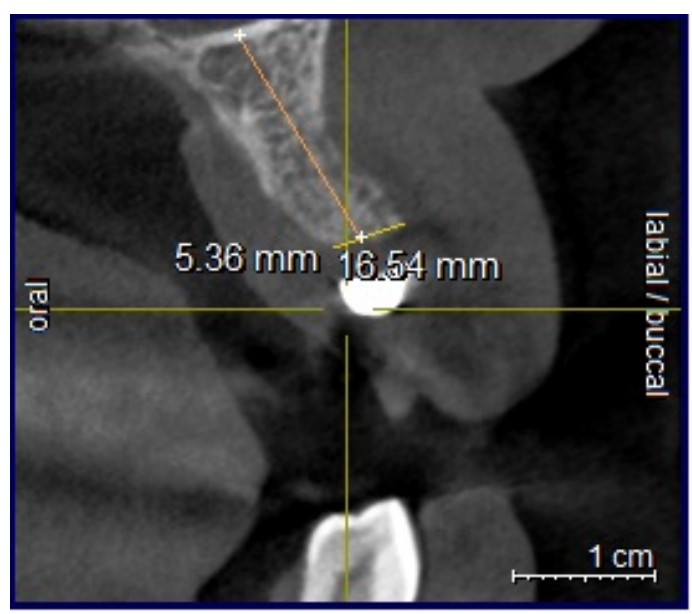

Figure 1.

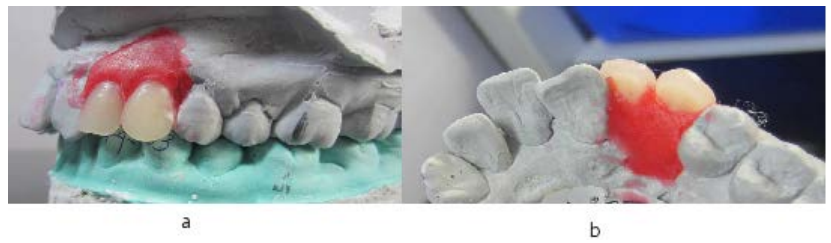

Figure 2.

\subsection{Surgical Phase}

Blood investigations were evaluated before placement of implant began. Mid crestal incision followed by flap 
elevation done in 22, 23 region [Figure 3]. Pilot drill of depth $13 \mathrm{~mm}$ was verified by depth gauge. Sequential drilling and bone tapping were done to place $3.8 * 13 \mathrm{~mm}$ Myriad Plus implant [Figure 4- Figure 7]. Bone defect in mid portion of labial cortical plate was filled with bone graft (Ossifi) covered by collagen membrane (Periocol) and flaps were sutured [Figure 8 a, Figure 8 b, Figure $8 c$ ]. Sutures were removed after a duration of one week.

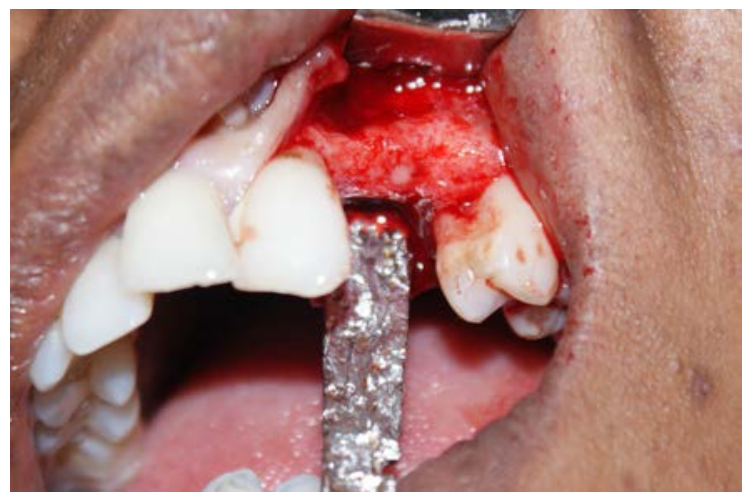

Figure 3.

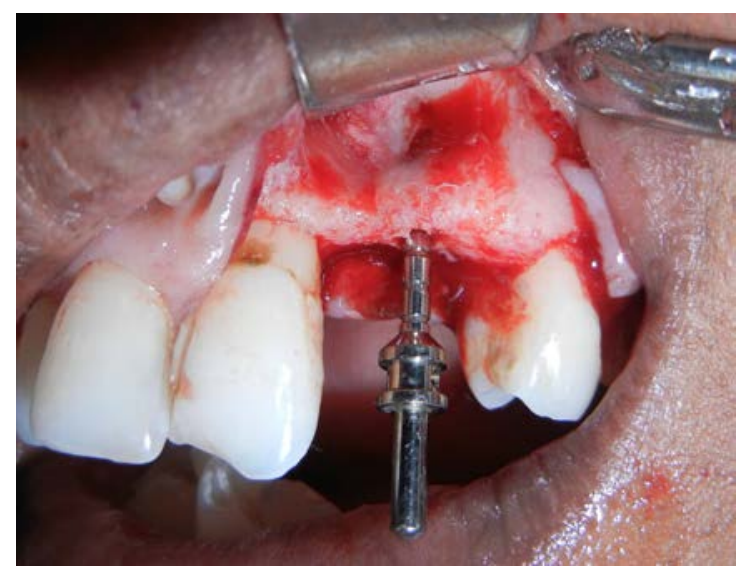

Figure 4.

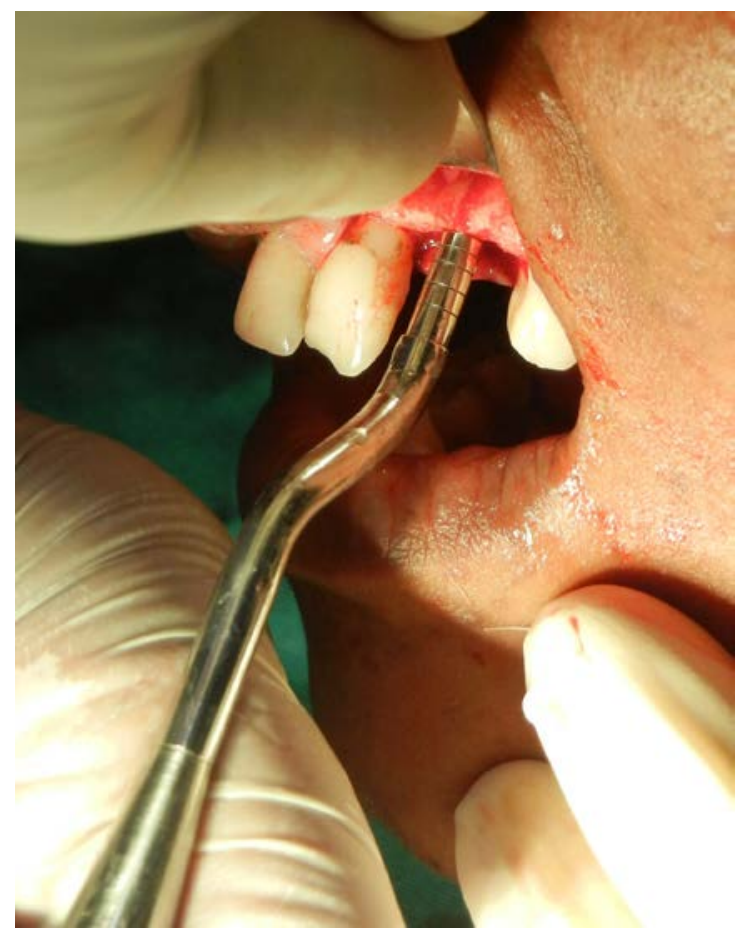

Figure 5.

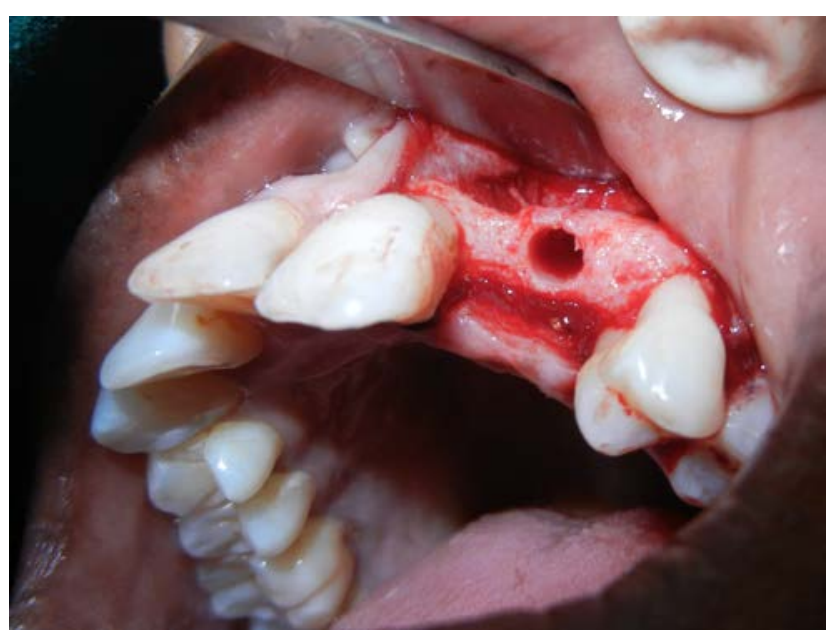

Figure 6.

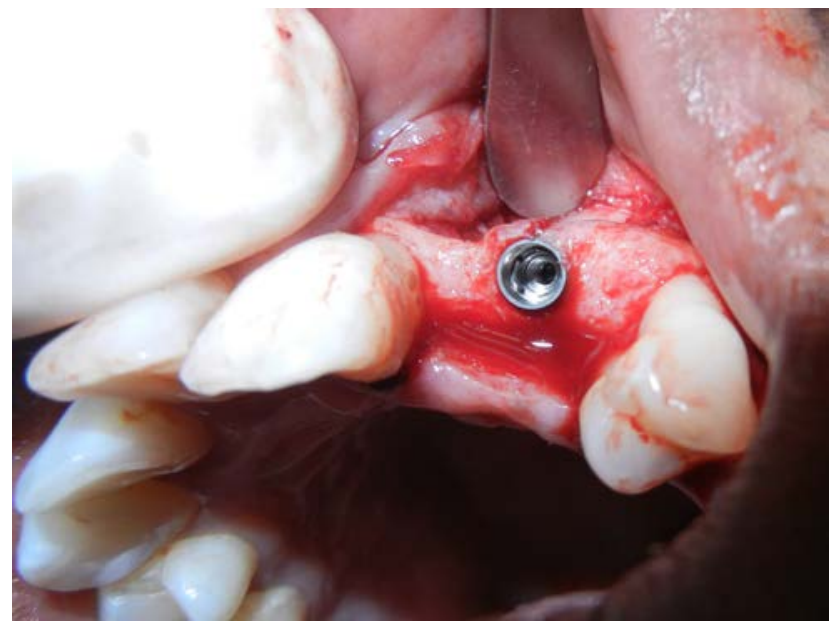

Figure 7.

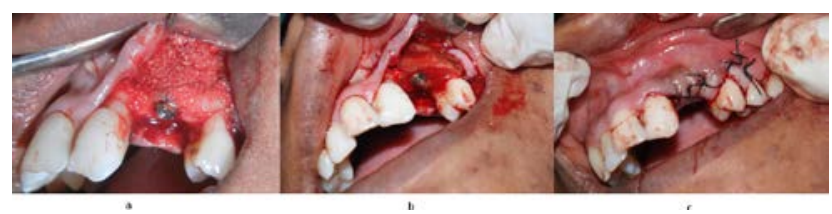

Figure 8.

\subsection{Restorative Phase}

After a follow up of 6 months duration, healing cap was placed and sutured [Figure 9 a \& Figure 9 b]. Suture removal done after one week followed by taking final impression with rubber base impression material (Aquasil, Denstply) having implant abutment and transfer cap in place [Figure 10 a, Figure 10 b, Figure 10 c, Figure 10 d]. Customized angulated abutment was casted in the lab and metal trial for Porcelain fused metal (PFM) crown was verified [Figure 11 a \& Figure 11 b]. After the final fabrication of PFM crown a bisque trial was done to remove interferences and final glazing was done. Final seating of the abutment with the crown was verified with an IOPA. Once seating is verified the abutment was tightened in the patient's mouth with a torque wrench calibrated to $30 \mathrm{~N}$ torque. After adequate isolation restoration was cemented with temporary luting cement (IRM) [Figure 12, Figure 13 a, Figure 13 b]. Proper oral hygiene instructions were given. The patient was reviewed after 2 weeks [Figure 14]. 


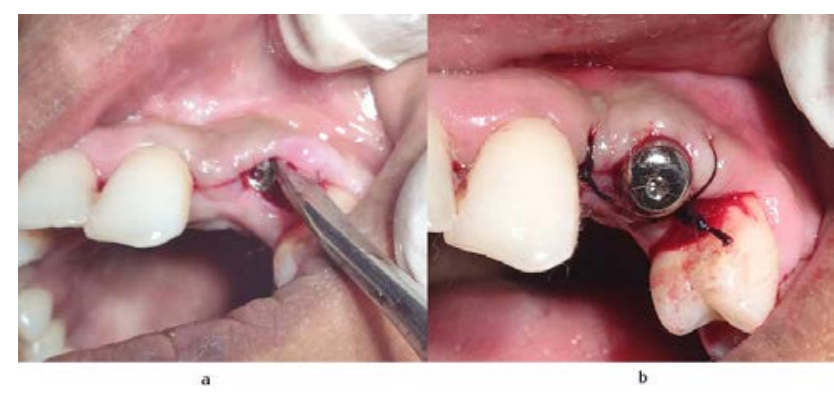

Figure 9.
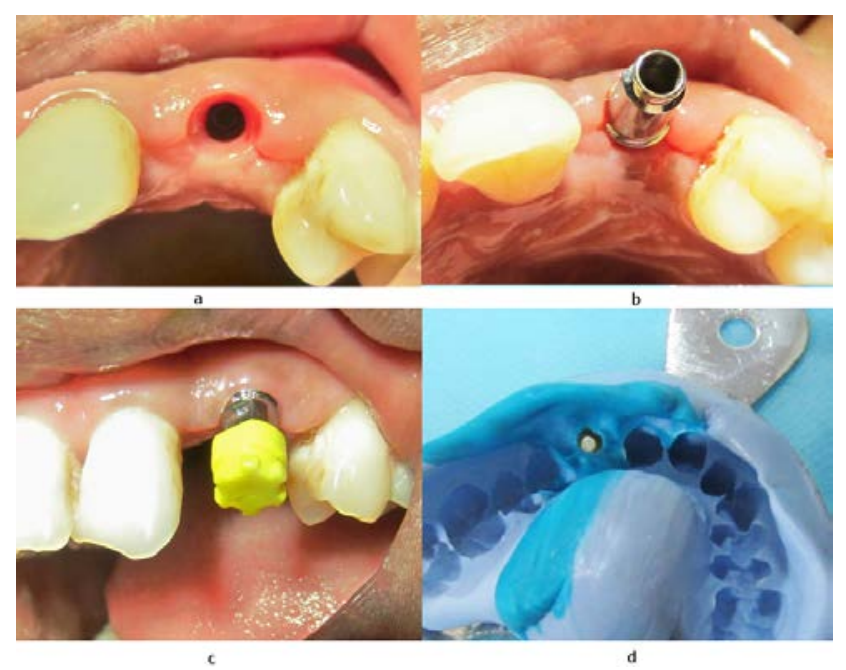

Figure 10.

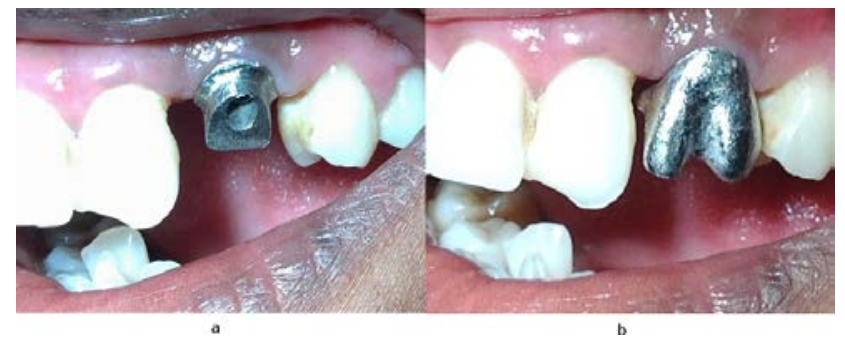

Figure 11.

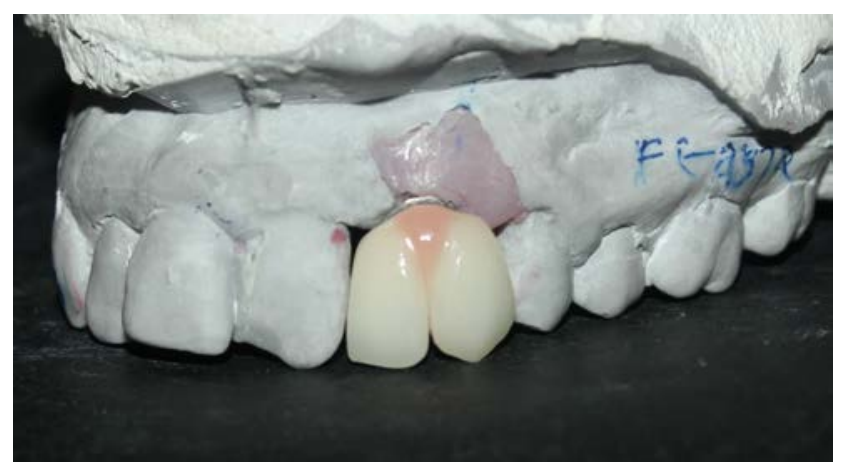

Figure 12.

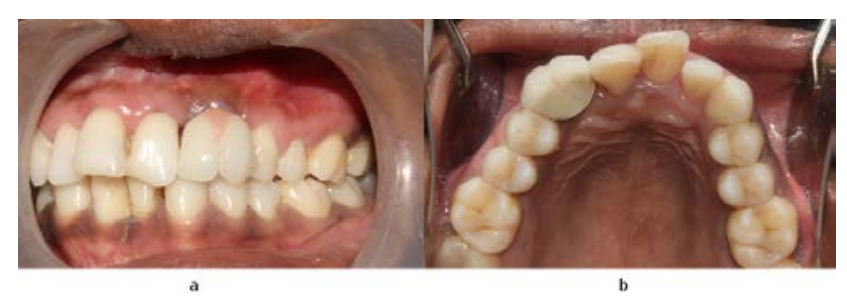

Figure 13.

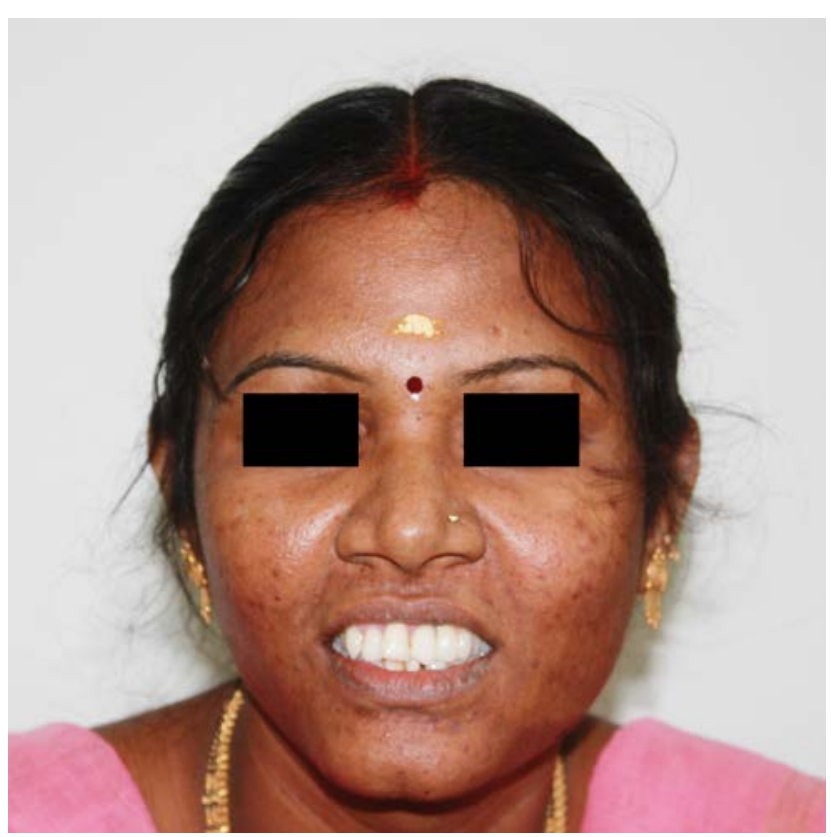

Figure 14.

\section{Discussion}

The Prosthetic treatment plan is definitely critical for the success of each case of rehabilitation, with the help of diagnostic wax up, we can determine the available space in mesio-distal and interocclusal regions, besides of the size of the teeth to be restored in the edentulous area. According to the study by Tarnow et al compared the presence or absence of papilla between 2 teeth, using the distance from the crest of the bone to the contact point between the teeth [4]. When a distance of $\leq 5 \mathrm{~mm}$ was achieved, the papilla filled the embrasure space $100 \%$ of the time. At $6 \mathrm{~mm}$, the papilla filled the embrasure space $55 \%$ of the time; at $7 \mathrm{~mm}$, the papilla filled the space $25 \%$ of the time. When an implant was placed adjacent to a natural tooth with $<5 \mathrm{~mm}$ between the contact point and the crest of the bone, the papilla was maintained [4]. It appears that the key to maintaining the interdental papilla is the bone level of the adjacent tooth, rather than the interproximal bone level of the implant [5]. In many clinical situations, implants have to be placed with buccal inclinations because of the dictates of bone morphology. This necessitates the use of angled abutments to axially realign abutments and to avoid unaesthetic buccal access apertures [6,7]. In two-stage angulated screw systems, custom castings are usually cumbersome and difficult to fabricate [8]. Prefabricated abutments often do not fit the clinical situation and have weak coping screws. Permanent cementation does not allow for retrievability. However a serious disadvantage if loosening of the abutment implant screw, porcelain fracture, or superstructure fracture occurs $[9,10,11,12]$. The occlusal equilibration was done with articulating paper in 22, 23 region to minimize the forces in the cantilevered tooth.

\section{Conclusion}

Placing a single tooth implant with a cantilevered tooth in the esthetic zone is a challenging task. This clinical 
report discusses the treatment done for restoring missing lateral incisor and canine using a single implant in a narrow edentulous space in a patient with generalized crowding.

\section{References}

[1] Herbert T Shillingburg, Sumiya Hobo, Lowell D Whitsett, Richard Jacobi, Susan E Brackett. Treatment planning for the replacement of missing teeth. Fundamentals of Fixed Prosthodontics. 3rd Edition: Quintessence; 1997: 85.

[2] Magne P, Magne M, Belser U. Natural and restorative oral esthetics. Part I: rationale and basic strategies for successful esthetic rehabilitations. J Esthet Dent 1993; 5 (4): 161-73.

[3] Magne P, Magne M, Belser U. Natural and restorative oral esthetics. Part II: esthetic treatment modalities. J Esthet Dent 1993; 5 (6): 239-46.

[4] Tarnow DP, Magner AW, Fletcher P. The effect of the distance from the contact point to the crest of bone on the presence or absence of the interproximal papilla. J Periodontol. 1992; 63 (12): 995-996.
[5] De Rouck T, Collys K, Cosyn J. Single-tooth replacement in the anterior maxilla by means of immediate implantation and provisionalization: a review. Int J Oral Maxillofac Implants. 2008; 23 (5): 897-904.

[6] ParelSM, Sullivan DY. Esthetics and Osseoimegralion. Dallas. TX; Osseointegration Seminars. 1989:83-93.

[7] Freidman JR. Five techniques for single tooth replacement on endosseous root form implants. J Prosthet Dent 1993: 69: 582-587.

[8] Yehuda Ganor, Baruch Indig, Martin Gross. Retrievable cemented crown options on implant-supported angled abutments. Quintessence Int 1996; 27: 679-684.

[9] Patterson EM, Johns RB. Theoretical analysis of the fatigue life of fixture screws in osseointegrated dental implants, Int J Oral Maxillofac Implants 1992: 7: 26-33.

[10] MeGlumphy EA, Robinson DM, Mendel DA. Implant superstructure: A comparison of ultimate failure force. Int J Oral Maxillofac Implants 1992: 7: 35-39.

[11] JaffinR, BemianC. The excessive loss of Brânemark fixtures in type IV bone: A five year analysis. S Periodontol 1991: 62: 2-4.

[12] Adell R, Eriksson B, Lekholm U et al. A long-term follow-up study of osseointegrated implants in the treatment of totally edentulous jaws. Int J Oral Maxillofac Implants 1990: 5: 347-359. 